\title{
Carreira proteana e satisfação no trabalho: Um estudo na Universidade Federal do Ceará
}

\section{Protean career and satisfaction at work: A study at the federal University of Ceará}

\author{
Lizy Manayra Santos Oliveira \\ Universidade Federal do Ceará (UFC) \\ email: lizymanayra@hotmail.com
}

\section{Rafael Straus Timbó Vasconcelos}

Universidade Federal do Ceará (UFC)

email:rafaelstraus@ufc.br

\author{
Augusto Cézar de Aquino Cabral \\ Universidade Federal do Ceará (UFC) \\ email:cabral@ufc.br
}

\section{Sandra Maria dos Santos}

Universidade Federal do Ceará (UFC)

email:smsantos@ufc.br

\section{RESUMO}

Neste estudo, objetivou-se investigar a relação entre as percepções dos servidores técnico-administrativos da Universidade Federal do Ceará quanto às atitudes da carreira proteana e a sua satisfação com o trabalho. Trata-se de uma pesquisa descritiva e quantitativa, realizada com 417 técnico-administrativos em educação por meio de um questionário que avalia as duas atitudes da carreira proteana - orientação por valores e autodirecionamento - e as cinco dimensões da satisfação no trabalho, de Siqueira (2008). A análise dos resultados indicou um forte autodirecionamento de carreira e uma moderada orientação por valores. Quanto às dimensões da satisfação no trabalho, os servidores mostraram-se, predominantemente, mais satisfeitos com o relacionamento entre os colegas e com a chefia, corroborando estudos anteriores realizados com servidores de outras instituições. Adicionalmente, análises de correlação e de árvores de decisão mostraram as características do perfil dos respondentes, as quais podem influenciar nas atitudes da carreira proteana.

Palavras-Chave: Carreira proteana. Novas configurações de carreira. Satisfação no trabalho. Setor público.

\section{ABSTRACT}

This study aimed to investigate the relationship between the perceptions of technical-administrative education in a federal university regarding the attitudes of the protean career and their satisfaction with work. This is a descriptive and quantitative research carried out with 417 technical-administrative in education through a questionnaire that evaluates the two attitudes of the protean career - values-drive and self-directed - and the five dimensions of work satisfaction of Siqueira (2008). The results indicated strong career self-directed and moderate value-drive. As to the dimensions of work satisfaction, the servants were predominantly more satisfied with the relationship between colleagues and the manager, corroborating previous studies performed with servants of other institutions. Additionally, correlation and decision tree analyzes have shown the characteristics of the respondent profile that may influence the attitudes of the protean career.

Key-words: Protean career. New career configurations. Satisfaction at work. Public sector. 


\section{INTRODUÇÃO}

O contexto contemporâneo vem sendo marcado por profundas transformações sociais e organizacionais, modificando o cenário do mercado de trabalho e exigindo novas formas de interação empregado-organização. Essas transformações começaram a se acentuar ao final dos anos de 1980, com o aumento da competição global e das mudanças na forma de empregabilidade e no desenvolvimento de carreira dos profissionais, provocando diversas alterações nos conceitos de carreira e de satisfação no trabalho. Nas últimas décadas, essa tendência também foi percebida no âmbito da administração pública (LOUREIRO; DA COSTA; FREITAS, 2012; CÁLCENA; CASADO, 2013).

Novos significados e denominações de carreira se apresentam para buscar refletir essa nova realidade. Dentre os novos modelos, destacam-se a carreira sem fronteiras, caracterizada pela ausência de fronteiras organizacionais; e a carreira proteana, definida pela autogestão de carreira (ANDRADE; KILIMNIK; PARDINI, 2011; BRISCOE; HALL; DEMUTH, 2006; CÁLCENA; CASADO, 2013). A carreira proteana envolve uma atitude orientada para valores pessoais, no sentido de que os valores de cada indivíduo geram direcionamento e mensuram sucesso na carreira; e uma atitude de autodireção na gestão de carreiras (BRISCOE; HALL; DEMUTH, 2006).

Silva, Balassiano e Silva (2014) observaram a existência de um comportamento independente, por meio do qual o indivíduo gerencia sua carreira, construindo suas perspectivas independentemente da estrutura organizacional e das premissas assumidas pelas organizações públicas. A carreira proteana é apontada por proporcionar maiores oportunidades e autonomia profissional, provocando, também, elevados custos sobre a saúde física e psicológica dos indivíduos, já que nem todos possuem as características e habilidades necessárias para atuarem nessa nova configuração de carreira. Por conseguinte, surge a necessidade de analisar a satisfação no trabalho diante desse aumento da carga de responsabilidade sobre o indivíduo e das demandas de adaptação às novas identidades profissionais (LOUREIRO; DA COSTA; FREITAS, 2012; CÁLCENA; CASADO, 2013).

A vertente satisfação no trabalho faz parte de um conjunto futuro de investigação relacionado à orientação de carreira proteana (NEVES; TREVISAN; JOÃO, 2013). Para Siqueira (2008), a satisfação no trabalho refere-se ao vínculo afetivo do indivíduo com o seu labor. Há evidências de que a satisfação tem relação com os fatores que envolvem salários e promoções; a convivência com os colegas e as chefias; e as realizações das tarefas.

Organizações públicas e privadas necessitam de ferramentas de gestão que impulsionem maior envolvimento das pessoas com o trabalho. Diante disso, além dos esforços da organização, os indivíduos precisam acumular conhecimentos e outras credenciais, devido à necessidade de eficiência e efetividade. Então, a relevância do estudo está fundamentada na importância da análise do grau de inclinação da carreira proteana e da satisfação no trabalho dos servidores para aprofundar o entendimento das atitudes de carreiras e da satisfação no trabalho no âmbito do serviço público.

O estudo contribui para o aprimoramento das temáticas e para o planejamento de ações efetivas de gestão por parte das universidades públicas federais. Ressalta-se que as universidades públicas apresentam peculiaridades concernentes à gestão de pessoas, visto que a Lei n. 11.091/2005 estabelece um plano de carreira dos cargos técnico-administrativos em educação. A Lei determina uma carreira única para cada cargo e a impossibilidade de promoção para um cargo diverso do aprovado no concurso público (BRASIL, 2005).

A pesquisa mostrou-se adequada também para analisar as peculiaridades da satisfação e do fenômeno do servidor burocrata proteano (CORDEIRO; ALBUQUERQUE, 2016; ANDRADE, 2018; SILVA; BALASIANO; SILVA, 2014). Diante do contexto exposto neste estudo, buscou-se responder à seguinte pergunta: como se dá a relação entre as percepções dos servidores técnico-administrativos da Universidade Federal do Ceará (UFC) quanto às atitudes da carreira proteana e à sua satisfação com o trabalho?

Nessa esteira, o objetivo traçado neste artigo é investigar a relação entre as percepções dos servidores técnico-administrativos da Universidade Federal do Ceará quanto às atitudes da carreira proteana e a sua satisfação com o trabalho. Foram definidos os seguintes objetivos específicos: 1) identificar as percepções dos servidores da UFC quanto às atitudes 
da carreira proteana; 2) verificar o nível de satisfação no trabalho dos servidores da UFC; 3 ) identificar a relação entre autodirecionamento e satisfação no trabalho; 4) verificar a relação entre orientação por valores e satisfação no trabalho; 5) identificar os perfis de respondentes com maior nível de autodirecionamento; e 6) identificar os perfis de respondentes com maior nível de orientação por valores.

Para o alcance dos objetivos propostos, foi realizado um estudo quantitativo por natureza e descritivo quanto aos fins, sendo a survey utilizada como método de coleta de dados junto aos servidores da UFC, dos quais foram obtidos 417 questionários validados.

Além desta introdução, quatro seções compõem este trabalho. Na seção 2, relata-se a revisão de literatura relacionada à carreira e à satisfação no trabalho; na seção 3, apresenta-se a metodologia deste trabalho; por sua vez, os resultados são abordados e analisados na seção 4; por fim, as considerações finais são apresentadas na última seção.

\section{REFERENCIAL TEÓRICO}

Nesta seção, são abordados os temas centrais que fundamentam a realização do presente estudo, contemplando carreiras, na perspectiva da carreira proteana, bem como o tema satisfação no trabalho.

\subsection{Carreiras}

O desenvolvimento do tema "carreira" teve início a partir do século XIX com o avanço da sociedade industrial capitalista liberal, sendo assim uma ideia historicamente recente. O progresso econômico e social contribuiu para o desenvolvimento, por todos, da noção de fazer carreira de forma igualitária. A ênfase maior do tema "carreira" apareceu com trabalhos que destacaram a importância do papel transformador do sujeito sobre as instituições no intuito de construir sua carreira (CHANLAT, 1995; KILIMNIK; VISENTIN, 2014).

Bendassoli (2009) destaca que existe uma ampla variedade de definições para o conceito de carreira. A coexistência dessas formas distintas de conceber o termo tem relação com as diferentes disciplinas que influenciaram o avanço da temática. Hall (2002, p. 12) conceitua carreira como uma "sequência individualmente percebida de atitudes e comportamentos associados com experiências e atividades relacionadas ao trabalho durante o período de vida de uma pessoa". Greenhaus e Callanan (1994) entendem a carreira como um padrão de experiências relacionadas com o trabalho, abrangendo o curso de vida de uma pessoa.

Importante destacar que, até os anos de 1970, ainda não existia um campo estabelecido para a análise das carreiras no âmbito dos estudos das organizações e da gestão em esfera internacional. Vigorava o modelo tradicional de carreira, e o ambiente era marcado pela estabilidade, enriquecimento, progresso e divisão sexual e social do trabalho, (ANDRADE; KILIMNIK; PARDINI, 2011; KILIMNIK; VISENTIN, 2014). A partir da década de 1980, com as rápidas mudanças no ambiente empresarial, o tema começou a sofrer alterações em sua concepção tradicional. Com isso, novos tipos de carreira passaram a surgir, cada qual com suas características. Entre os modelos contemporâneos de carreira, destaca-se o construto carreira proteana. Sobre isso, destaca-se que a carreira proteana tem como postulado a responsabilidade do indivíduo pelo autogerenciamento da carreira e a importância dos valores pessoais na tomada de decisão. (HALL, 2002; BRISCOE; HALL; DEMUTH, 2006).

No subtópico seguinte, o construto carreira proteana é abordado de forma mais detalhada, destacando suas principais características e dimensões. O modelo de carreira proteana foi escolhido para orientar o presente estudo, já que Silva, Balassiano e Silva (2014) concluíram que os servidores públicos apresentam um comportamento independente e autônomo em relação às premissas das organizações públicas.

\subsubsection{Carreira proteana}

A carreira proteana é um conceito que representa uma nova configuração de carreira, advinda das mudanças ocorridas no mercado de trabalho e que passaram a demandar novas formas de relacionamento entre organização e empregados; bem como versa sobre o planejamento do desenvolvimento dos profissionais (NEVES; TREVISAN; JOÃO, 2013).

Segundo Martins (2011), a carreira proteana está baseada no mito de Proteu, que é conhecido por 
mudar sua forma de acordo com as circunstâncias, apresentando elementos que podem ser metaforicamente relacionados ao profissional contemporâneo, capaz de autogerenciar sua trajetória com eficácia e se adaptar às circunstâncias do ambiente organizacional. Hall (2004) descreve a carreira proteana como aquela em que a pessoa é responsável por sua trajetória profissional e quando os valores pessoais dirigem as decisões de carreira. O autor destaca que os critérios de sucesso deixam de ser objetivos (posição e salário) e passam a ser subjetivos (sucesso psicológico). Então, essa carreira é caracterizada por profissionais que assumem a condução dela própria. Assim, aspectos comuns da carreira tradicional, como a lealdade e o comprometimento com a organização, que geravam estabilidade de emprego, são menos valorizados (HALL, 1996; ANDRADE, 2018).

Segundo Briscoe, Hall e DeMuth (2006), as escalas referentes ao modelo de carreira proteana medem as seguintes atitudes, como demonstrado no quadro 01 .

Quadro 01 Dimensões da carreira proteana

\begin{tabular}{l|l}
\multicolumn{1}{c|}{ Dimensões } & \multicolumn{1}{c}{ Definições } \\
\hline Autodirecionamento & $\begin{array}{l}\text { A gestão da carreira direcionada pelo indivíduo que cria suas próprias oportunidades de desenvolvimento. Está } \\
\text { relacionado à adaptabilidade e à responsabilidade pela própria carreira }\end{array}$ \\
\hline Orientação por valores & $\begin{array}{l}\text { O indivíduo prioriza seus valores pessoais ao estabelecer prioridades e objetivos; e ao tomar suas decisões de } \\
\text { carreira. }\end{array}$ \\
\hline
\end{tabular}

Fonte: Briscoe, Hall e DeMuth (2006).

Conforme Silva (2009), um indivíduo que não possui atitudes da carreira proteana costuma não desenvolver seus padrões internos, ficando mais inclinado a tomar emprestado padrões externos. Por conseguinte, os profissionais buscam direcionamento e assistência em gestão de carreiras, em oposição a desenvolver um comportamento proativo e independente.

Ainda de acordo com Silva, Balassiano e Silva (2014), os servidores públicos estão construindo suas perspectivas de carreira independentemente da estrutura organizacional à qual pertencem. Além disso, os autores constataram que os profissionais estudados buscam constantemente outras atividades, mas permanecem em organizações públicas, sugerindo a existência do burocrata proteano: indivíduo que se submete a uma lógica organizacional de carreira, mas que mantém uma independência em relação às organizações públicas no decorrer de suas trajetórias profissionais. Andrade (2018) acrescenta que o servidor utiliza as oportunidades e benefícios do plano de cargos e carreiras da universidade, como a possibilidade de afastamento para estudos stricto sensu, capacitação contínua, entre outras, para articular seu tempo laboral com outras atividades, como a docência, por legalidade na esfera privada.

\subsection{Satisfação no trabalho}

A satisfação no trabalho é uma variável muito significativa na conjuntura organizacional. A partir dela, é possível a compreensão de outros fenômenos no ambiente organizacional se inferirmos que a satisfação está associada a índices melhores de efetividade dos trabalhadores (SILVA; CASTRO; DOS-SANTOS, 2018). Necessidades humanas, como aceitação, reconhecimento e realização, são aspectos considerados no entendimento da satisfação (MOTTA, 1979). A teoria de Herzberg (1997) também destaca a importância desses aspectos para a satisfação no trabalho. Assim, o interesse pelo tema cresce à medida em que as emoções são consideradas essenciais para avaliar envolvimento e desempenho organizacional com bem-estar, qualidade de vida e saúde (BIZARRIA et al., 2018).

Locke (1976) conceituou a satisfação no trabalho como um estado emocional, positivo ou de prazer, resultante de um trabalho ou de suas experiências de trabalho. Esse conceito ainda é bastante utilizado, no entanto o tema sofreu algumas mudanças ao longo do tempo. Siqueira (2008) destaca que, inicialmente, a satisfação estava relacionada a uma motivação que impulsionava os trabalhadores a demonstrarem comportamentos engajados no trabalho, possibilitando o 
aumento do desempenho e a redução do absenteísmo. Com o tempo, os estudos evoluíram para a ideia de satisfação como uma atitude (entendendo que o trabalhador satisfeito seria um trabalhador produtivo). Temos, ainda, a vertente banhada em pressupostos humanistas e sociais, os quais consideram que os sentimentos emergentes do local de trabalho se espraiam para a vida social, familiar e pessoal do indivíduo, afetando seus níveis de bem-estar e, inclusive, sua saúde física e mental. (SIQUEIRA, 2008).

Siqueira (2008), com base nas leituras de Locke (1976), apresentou uma escala de satisfação no trabalho a partir da noção de que esse fenômeno reflete um estado emocional/afetivo prazeroso, o qual tem relação com as experiências positivas no trabalho e, ao mesmo tempo, envolve aspectos individuais, como os valores e as expectativas em relação ao trabalho e à organização. A autora verificou que há fatores que contribuem pouco para explicar variações em níveis de satisfação no trabalho - podemos citar as características pessoais do trabalhador, do ambiente e da estrutura das organizações - enquanto fatores do contexto sócio-organizacional teriam impacto mais forte (valores organizacionais, percepções de justiça, de suporte e de reciprocidade, emergentes das relações de trocas sociais e econômicas entre trabalhadores e organizações). Satisfação no trabalho seria, assim, um sentimento bastante vulnerável às políticas e práticas gerenciais. Nesse sentido, é importante investigar a satisfação no trabalho para que sejam avaliados o quanto os retornos oferecidos pela empresa na forma de salários e promoção, o quanto a convivência com os colegas e as chefias e o quanto as tarefas possibilitam, ao empregado, sentimentos gratificantes (SIQUEIRA, 2008).

Para a execução deste artigo, foi utilizada a escala de satisfação no trabalho, de Siqueira (2008), construída e validada no Brasil, possuidora de uma visão multidimensional de satisfação no trabalho, cobrindo cinco dimensões teóricas (satisfação com os colegas, satisfação com a chefia, satisfação com o salário, satisfação com as promoções e satisfação com a natureza do trabalho): as duas primeiras agrupam variáveis relacionadas ao ambiente social e à organização e capacidade profissional do chefe; as duas seguintes reúnem variáveis relacionadas ao contentamento com o salário, se comparado com o quanto o indivíduo trabalha, e à percepção sobre as políticas de gestão de pessoas; a última envolve a satisfação pelas tarefas.

\subsection{Estudos anteriores sobre carreira proteana e satisfação no trabalho no setor público}

Nesta subseção, visa-se a apresentar resultados de pesquisas desenvolvidas sobre as temáticas do presente trabalho. Com a análise desses estudos, percebe-se que o tema de satisfação no trabalho não é muito explorado conjuntamente com as pesquisas sobre carreira proteana. No entanto, entender a satisfação no trabalho é importante, já que as instituições buscam ter funcionários que trabalhem satisfeitos.

$\mathrm{O}$ quadro 02 apresenta os principais estudos sobre as temáticas que orientaram o presente trabalho. Esses estudos foram selecionados com base nos artigos encontrados na plataforma SPELL nos últimos cinco anos.

As pesquisas sobre as alterações nos formatos, conteúdos e perspectivas das carreiras estão mais voltadas para o setor privado, sem tratar de especificidades do âmbito público (SILVA; BALASSIANO; SILVA, 2014; ANDRADE, 2018).

No Brasil, Silva, Balassiano e Silva (2014) evidenciaram indivíduos gerenciando suas carreiras de maneira autônoma em relação às premissas assumidas pelas organizações públicas. Posteriormente, Pinho, Kilimnik e Andrade (2015) verificaram a influência da estrutura matricial - integrante do Sistema Integrado de Gestão (SIG) da Empresa Pública de Assistência Técnica e Extensão Rural (EMATER-MG) em comparação com os profissionais que permanecem em sua estrutura tradicional. Por meio da pesquisa de natureza quantitativa, constatou-se que a maior parte dos profissionais pesquisados se identifica com a carreira proteana, independentemente do tipo de estrutura a que estão vinculados.

Andrade (2018) analisou o grau de comprometimento com a carreira de técnico-administrativo em educação (TAE) sob a influência do fenômeno burocrata proteano na percepção de servidores técnico-administrativos lotados em um centro acadêmico de uma universidade federal. A partir dos resultados, pode-se concluir que mais de $65 \%$ dos respondentes já 


\begin{tabular}{|c|c|c|c|c|}
\hline Autores/Ano & Objetivo & $\begin{array}{l}\text { Referencial } \\
\text { Teórico }\end{array}$ & Aspectos metodológicos & Resultados alcançados \\
\hline $\begin{array}{l}\text { Andrade } \\
\text { (2018) }\end{array}$ & $\begin{array}{l}\text { Analisar o comprometimento } \\
\text { com a carreira de técnico-admi- } \\
\text { nistrativo em educação sob a } \\
\text { influência do fenômeno de } \\
\text { burocrata proteano. }\end{array}$ & $\begin{array}{l}\text { Carreira proteana } \\
\text { de Hall (1996). }\end{array}$ & $\begin{array}{l}\text { Pesquisa de levantamento } \\
\text { (survey) com abordagem } \\
\text { quantitativa } \\
\text { de corte transversal com } 67 \\
\text { técnico-administrativos em } \\
\text { educação. }\end{array}$ & $\begin{array}{l}\text { A maioria dos respondentes afir- } \\
\text { mou que tem interesse em con- } \\
\text { tinuar na carreira de TAE (68,7\%). } \\
\text { Foi evidenciada uma tendência } \\
\text { recentemente na carreira públi- } \\
\text { ca, que é a intencionalidade do } \\
\text { servidor público gerenciar suas } \\
\text { carreiras de maneira autônoma } \\
\text { em relação às premissas das } \\
\text { organizações públicas. }\end{array}$ \\
\hline $\begin{array}{l}\text { Barbosa et al. } \\
\text { (2016) }\end{array}$ & $\begin{array}{l}\text { Analisar a satisfação no } \\
\text { trabalho por meio da Escala } \\
\text { de Satisfação no Trabalho } \\
\text { (EST) construída e validada por } \\
\text { Siqueira (2008) }\end{array}$ & Siqueira (2008). & $\begin{array}{l}\text { Pesquisa do tipo levantamento } \\
\text { (survey) com abordagem quan- } \\
\text { titativa com } 182 \text { funcionários. } \\
\text { Análise dos dados com o uso } \\
\text { de técnicas estatísticas. }\end{array}$ & $\begin{array}{l}\text { A chefia teve uma forte influên- } \\
\text { cia sobre a satisfação dos cola- } \\
\text { boradores do hospital público, } \\
\text { seguidos pelo relacionamento } \\
\text { interpessoal e a promoção com } \\
\text { impactos representativos na } \\
\text { satisfação. }\end{array}$ \\
\hline $\begin{array}{l}\text { Pinho, } \\
\text { Kilimnik e } \\
\text { Andrade } \\
\text { (2015). }\end{array}$ & $\begin{array}{l}\text { Verificar a influência da estrutura } \\
\text { matricial - integrante do Siste- } \\
\text { ma Integrado de Gestão (SIG) } \\
\text { da EMATER-MG - no compro- } \\
\text { metimento com a carreira dos } \\
\text { profissionais que atuam como } \\
\text { gestores, em comparação com } \\
\text { os profissionais que permane- } \\
\text { cem em sua estrutura tradicional }\end{array}$ & $\begin{array}{l}\text { Carreira com base } \\
\text { em Hall (1996). }\end{array}$ & $\begin{array}{l}\text { Pesquisa de natureza quanti- } \\
\text { tativa, realizada por meio de } \\
\text { estudo descritivo de caso com } \\
32 \text { profissionais que atuam } \\
\text { na estrutura matricial e com } \\
110 \text { profissionais da estrutura } \\
\text { tradicional. }\end{array}$ & $\begin{array}{l}\text { A maior parte dos profissionais } \\
\text { pesquisados identifica-se com a } \\
\text { carreira proteana, independen- } \\
\text { temente do tipo de estrutura a } \\
\text { que estão vinculados. }\end{array}$ \\
\hline $\begin{array}{l}\text { Silva, } \\
\text { Balassiano e } \\
\text { Silva (2014). }\end{array}$ & $\begin{array}{l}\text { Compreender como são cons- } \\
\text { truídos os processos pessoais } \\
\text { de carreira de servidores com } \\
\text { carreiras técnicas de nível } \\
\text { superior no setor público, frente } \\
\text { às diferentes perspectivas de } \\
\text { carreiras articuladas no contex- } \\
\text { to social contemporâneo. }\end{array}$ & $\begin{array}{l}\text { Carreiras na } \\
\text { perspectiva de } \\
\text { Bendassolli, (2009) } \\
\text { e Chanlat (1995). }\end{array}$ & $\begin{array}{l}\text { Estudo de caso descritivo, com } \\
\text { abordagem qualitativa nos } \\
\text { servidores de uma Secretaria } \\
\text { de Estado. O tratamento dos } \\
\text { dados foi realizado por meio da } \\
\text { análise de conteúdo. }\end{array}$ & $\begin{array}{l}\text { Foi possível evidenciar indivídu- } \\
\text { os gerenciando suas carreiras de } \\
\text { maneira autônoma em relação } \\
\text { às premissas assumidas pelas } \\
\text { organizações públicas, em } \\
\text { composições de elementos que } \\
\text { caracterizam o que foi aqui cha- } \\
\text { mado de burocrata proteano. }\end{array}$ \\
\hline $\begin{array}{l}\text { Brandão et al. } \\
\text { (2014). }\end{array}$ & $\begin{array}{l}\text { Identificar os fatores para satis- } \\
\text { fação no trabalho na Superin- } \\
\text { tendência Regional do Trabalho } \\
\text { e Emprego (SRTE/CE). }\end{array}$ & $\begin{array}{l}\text { Teoria bifatorial de } \\
\text { Herzberg (1997) e } \\
\text { Motta (1979). }\end{array}$ & $\begin{array}{l}\text { Pesquisa survey com auditores } \\
\text { fiscais do trabalho, servidores } \\
\text { administrativos e estagiários. }\end{array}$ & $\begin{array}{l}\text { Estão mais satisfeitos, de forma } \\
\text { geral, com a supervisão e com } \\
\text { os relacionamentos interpes- } \\
\text { soais. }\end{array}$ \\
\hline
\end{tabular}

Fonte: Elaborado pelos autores (2018).

exercem ou têm a intenção em exercer alguma atividade paralelamente à carreira de TAE. Os dados da pesquisa corroboram com o estudo realizado por Silva, Balassiano e Silva (2014) no contexto atual do serviço público.

Em pesquisa realizada com servidores da SRTE/ CE, Brandão et al. (2014) concluíram que os servidores estavam mais satisfeitos com a supervisão e com os relacionamentos interpessoais. Já Barbosa et al. (2016) concluíram que os funcionários do Hospital Público de Campo Maior, no Piauí, estão mais satisfeitos com a chefia, com os colegas de trabalho e com as promoções recebidas.
Analisando as contribuições de estudos anteriores, é possível perceber que a presente pesquisa se distingue por analisar a relação entre as atitudes da carreira proteana e as dimensões da satisfação no trabalho dos servidores técnico-administrativos da Universidade Federal do Ceará. O modelo de carreira proteana e as dimensões da satisfação no trabalho são construtos com bases teóricas diferentes que analisam o perfil do indivíduo e seu nível de satisfação com os fatores do trabalho, respectivamente. Dessa forma, uma discussão conjunta sobre eles também tem grande importância e pode trazer novas informações 
e significados para melhoria dos processos pessoais de carreiras no setor público frente às necessidades de adaptação ao contexto social contemporâneo. Considerando as análises apresentadas, surgem as hipóteses desta pesquisa:

1. Os servidores públicos técnico-administrativos da UFC alinham-se às atitudes da carreira proteana;

2. Os servidores públicos técnico-administrativos da UFC apresentam maior satisfação com as seguintes dimensões: relacionamento com os colegas e relacionamento com a chefia imediata;

3. Existe relação entre o autodirecionamento e as dimensões da satisfação no trabalho;

4. Existe relação entre a dimensão orientação por valores e as dimensões da satisfação no trabalho;

5. Os servidores públicos técnico-administrativos da UFC com maior nível de autodirecionamento são aqueles com menos tempo de trabalho ao longo da carreira;

6. Os servidores públicos técnico-administrativos da UFC com maior nível de orientação por valores possuem também forte autodirecionamento.

\section{METODOLOGIA}

Quanto à natureza, a pesquisa é quantitativa, pois os dados empíricos foram processados quantitativamente após uma coleta objetiva e um tratamento também objetivo. Destaca-se que a pesquisa quantitativa se trata de um levantamento de tendências, atitudes ou opiniões de uma população, a partir do estudo de uma amostra (CRESWELL, 2010).

Quanto aos meios, caracteriza-se pela aplicação de um survey, buscando entender qual a percepção dos servidores da UFC. A técnica conhecida como survey "trata-se de um levantamento junto às fontes primárias, geralmente através de aplicação de questionários para grande quantidade de pessoas" (MARTINS, 2007, p. 36).

Quanto aos fins, trata-se de uma pesquisa descritiva, pois descreve o nível de satisfação dos indivíduos com seu trabalho, além de delinear o perfil da sua carreira, se está alinhada ao conceito de carreira proteana. Conforme Gil (2009, p. 42), "as pesquisas descritivas têm como objetivo primordial a descrição das características de determinada população ou fenômeno ou, então, o estabelecimento de relações entre variáveis".

A população consiste na totalidade dos servidores técnico-administrativos da UFC de todas as áreas. De acordo com a Pró-Reitoria de Gestão de Pessoas da UFC (2018), há 3.422 servidores técnico-administrativos na universidade. O questionário eletrônico obteve 564 respostas, das quais 147 foram desconsideradas, pois se tratavam de respostas de professores, os quais não são objeto deste trabalho. Assim, a amostra consistiu em 417 respostas válidas, o que corresponde a $12,18 \%$ dos servidores técnico-administrativos. A amostra é caracterizada por conveniência, já que foi escolhida pela disponibilidade de acesso aos servidores dessa instituição.

O processo de coleta de dados ocorreu de forma eletrônica, no período de 12 de julho de 2018 a 13 de agosto do mesmo ano. O questionário foi hospedado no google forms e o link encaminhado foi enviado a cada respondente, por e-mail, pela Pró-Reitoria de Gestão de Pessoas da UFC, que autorizou a realização do estudo com os servidores. No corpo do e-mail, havia um convite para a participação no survey.

Para a realização da pesquisa, optou-se pelo uso de um instrumento composto por três partes: escala de atitude da carreira proteana, de Briscoe, Hall e DeMuth (2006); escala de satisfação no trabalho, de Siqueira (2008); e questões adicionais que visaram a levantar informações demográficas e sociais dos respondentes. No Brasil, o instrumento de escala da carreira proteana foi traduzido e adaptado culturalmente por Silva (2009). Após esses processos, o instrumento passou por uma etapa de validação semântica e por um teste de consistência para verificar a validade do questionário. Cordeiro e Albuquerque (2016) realizaram pequenos ajustes nos termos ou na ordem destes para melhorar o entendimento das questões pelos respondentes; a mais, realizaram uma validação com o objetivo de confirmar os achados de Silva (2009) perante uma amostra composta de 2.376 jovens da geração Y e de garantir a validade do instrumento para o seu estudo. 
Segundo Cordeiro e Albuquerque (2016), a partir dos resultados das análises fatoriais e do alfa de Cronbach foi possível constatar a validade e a confiabilidade do instrumento utilizado, sugerindo a utilização dessa escala em futuros estudos nacionais sobre as novas carreiras e estimulando a produção do conhecimento nacional em carreiras.

Desse modo, a primeira parte do quadro contém 14 questões que mensuram as atitudes do entrevistado quanto às duas dimensões da carreira proteana (autodirecionamento de carreira e autovalores). Essas questões serão respondidas a partir de uma escala Likert de cinco pontos que variam de Discordo Totalmente a Concordo Totalmente.

Para a satisfação no trabalho, empregou-se a escala de Siqueira (2008) na versão reduzida, a qual foi validada pela autora com 15 itens. Esse construto compreende cinco dimensões: satisfação com os colegas, com a chefia, com as promoções, com o salário e com a natureza do trabalho. No instrumento de coleta, cada uma das dimensões se mede por meio de três itens, e as respostas dos sujeitos são obtidas por meio de uma escala de 7 pontos $(1=$ totalmente insatisfeito; 2 = muito insatisfeito; 3 = insatisfeito; 4 = indiferente; 5 = satisfeito; 6 = muito satisfeito; 7 = totalmente satisfeito). No presente estudo, realizou-se uma adaptação para uma escala de 5 pontos, visando a padronizar com a escala Likert de cinco pontos da escala de carreira proteana.

Como decorrência da utilização de dados quantitativos, fez-se necessário o uso de métodos estatísticos. A utilização desses métodos visou a obter, organizar, analisar e apresentar certos dados numéricos de fatos, fenômenos ou problemas (MARTINS, 2007). Dessa maneira, a análise dos dados foi realizada por meio de um programa computacional de tratamento estatístico: Statistical Package for the Social Science (SPSS). Nesse programa, a amostra foi analisada, em termos numéricos e percentuais, a partir dos dados sociodemográficos obtidos. Posteriormente, para avaliar a normalidade da amostra, nesta pesquisa, utilizou-se o teste Kolmorov-Smirnov. A aplicação desse teste nos dados da amostra determinou se os valores dos escores seguem uma distribuição de frequência normal. Com essa indicação, é possível definir qual tipo de teste estatístico deve ser utilizado na análise.
Tabela 01 Teste de normalidade

\begin{tabular}{l|c|c}
\hline & $\begin{array}{c}\text { Kolmogorov- } \\
\text {-Smirnov }\end{array}$ & Valor p \\
\hline Autodirecionamento & 2,8145 & 0,00 \\
\hline Orientação por valores & 2,6126 & 0,00 \\
\hline Satisfação com os colegas & 5,2621 & 0,00 \\
\hline Satisfação com o salário & 3,3854 & 0,00 \\
\hline Satisfação com a chefia & 4,5670 & 0,00 \\
\hline Satisfação com a natureza do trabalho & 4,6214 & 0,00 \\
\hline Satisfação com as promoções & 2,0300 & 0,00 \\
\hline
\end{tabular}

Fonte: Elaborada pelos autores (2018).

Conforme a tabela 01, observou-se que todos os construtos formados não apresentaram distribuição normal. Desse modo, para verificar a correlação entre as variáveis, utilizou-se o teste não paramétrico de correlação de Spearman

Por fim, foi realizada a distribuição de frequências dos dados, as médias, os desvios-padrão e os percentis da escala de carreira proteana e escala de satisfação no trabalho. Ademais, utilizou-se a correlação para relacionar as duas escalas e a análise de árvore de decisão.

\section{ANÁLISE DOS RESULTADOS}

Os resultados obtidos na pesquisa são apresentados e exibidos de forma segmentada para explanar adequadamente os processos metodológicos realizados no estudo. Inicia-se com a representação da amostra, descrevendo as características sociodemográficas. $\mathrm{Na}$ sequência, serão apresentados o teste de normalidade da amostra, o resultado do teste de correlação e o teste de confiabilidade interna dos itens do questionário.

\subsection{Descrição da amostra}

De acordo com os resultados coletados, por meio do questionário aplicado, o número total de participantes da pesquisa foi 417 servidores de diversos cargos da organização. Com a análise da amostra, percebeu-se que o grupo de assistentes em administração foi que apresentou maior representa- 
tividade, com 22,3\% do total. Em seguida, os cargos de administrador e enfermeiro apresentaram, cada um, percentual de 7,19\%.

Quanto à idade, percebe-se que mais de $60 \%$ dos respondentes possuem de 25 a 44 anos. Quanto à escolaridade, observa-se que a maioria é pós-graduada $(69,5 \%)$, enquanto a quantidade de graduados é de $24,7 \%$. Portanto, constata-se um grupo bastante qualificado. Além disso, cerca de metade dos respondentes possui mais de dez anos de tempo trabalhado.

Tabela 02 Frequência por tempo de trabalho

\begin{tabular}{l|c|c|c}
\hline & Frequência & Percentual & $\begin{array}{c}\text { Percentual } \\
\text { acumulado }\end{array}$ \\
\hline de $\mathbf{0}$ a $\mathbf{3}$ anos & 49 & $11,8 \%$ & $11,8 \%$ \\
\hline de $\mathbf{3}$ a $\mathbf{5}$ anos & 58 & $13,9 \%$ & $25,7 \%$ \\
\hline de $\mathbf{5}$ a $\mathbf{1 0}$ anos & 94 & $22,5 \%$ & $48,2 \%$ \\
\hline de $\mathbf{1 0}$ a $\mathbf{2 0}$ anos & 104 & $24,9 \%$ & $73,1 \%$ \\
\hline mais de $\mathbf{2 0}$ anos & 107 & $25,7 \%$ & $98,8 \%$ \\
\hline de $\mathbf{1 0}$ a $\mathbf{2 0}$ anos & 5 & $1,2 \%$ & $100,0 \%$ \\
\hline
\end{tabular}

Fonte: Elaborada pelos autores (2018).

Na tabela 02, são apresentados os dados completos da frequência por tempo de trabalho. Ressalta-se que a faixa pesquisada com maior número de respondentes $(25,7 \%)$ tem mais de vinte anos de serviço.

\subsection{Atitudes da carreira proteana}

Conforme prossegue a análise descritiva das respostas da amostra sobre as afirmativas referentes à carreira proteana, observa-se que a amostra está mais favorável aos seguintes indicadores, inseridos na atitude de autodirecionamento:

a) Quando oportunidades de desenvolvimento não me foram oferecidas por minha empresa, busquei-as por mim mesmo;

b) Sou responsável pelo sucesso ou fracasso em minha carreira;

c) Liberdade para escolher minha própria trajetória de carreira é um dos meus valores mais importantes.
Quanto à atitude de orientação por valores, constata-se que a seguinte afirmativa se destaca pelo seu nível de concordância: sigo a minha própria consciência se a empresa solicitar que eu faça algo que seja contra os meus valores. Dessa maneira, é possível perceber que os servidores estão estabelecendo prioridades e objetivos de carreira, assumindo a responsabilidade por elas e seguindo sua própria consciência diante de solicitações que sejam contra os seus valores.

$\mathrm{Na}$ tabela 03, são apresentados todos os resultados referentes às afirmativas sobre carreira proteana $\mathrm{e}$ suas duas atitudes (autodirecionamento e orientação por valores).

Para analisar as atitudes da carreira proteana e as dimensões da satisfação no trabalho, os resultados foram segmentados na tabela 04 . Visando a viabilizar a discussão dos resultados nos escores de uma forma mais objetiva, foram classificadas as médias obtidas em cada grupo em: fraca (quando a média está abaixo de $25 \%$ do escore máximo); regular (quando a média está entre $25 \%$ e $50 \%$ do escore máximo); moderada (quando a média está entre 50 e 75\% do escore máximo); forte (quando a média está acima de $75 \%$ do escore máximo).

Pela análise descritiva, visualizando as médias, desvios e percentis, constatou-se que tanto as atitudes da carreira proteana quanto as dimensões de satisfação apresentaram valores percentuais acima de $50 \%$, sendo consideradas moderadas ou fortes. Os resultados obtidos permitem demonstrar que a atitude de autodirecionamento de carreira destaca-se como a característica mais forte na amostra estudada. Por sua vez, a atitude de orientação por valores apresenta média moderada.

Então, por meio dos resultados, confirma-se a primeira hipótese desta pesquisa, a partir da qual é possível constatar que os servidores públicos técnico-administrativos da UFC se alinham à ideia da carreira proteana. Andrade, Kilimnike Pardini (2011) afirmam que a maior inclinação dos pesquisados em direção aos valores da carreira proteana reflete uma valorização de um processo de carreira autogerenciado, com critérios de satisfação definidos pelos indivíduos e não pelas organizações. 
Tabela 03 Afirmativas sobre a carreira proteana

\begin{tabular}{|c|c|c|c|c|c|c|}
\hline Dimensões & Variáveis & 1 & 2 & 3 & 4 & 5 \\
\hline \multirow{8}{*}{ 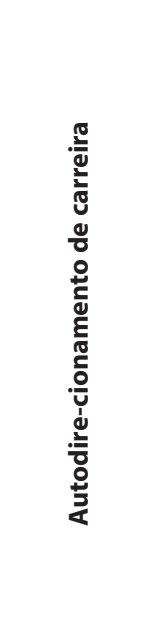 } & $\begin{array}{l}\text { Quando oportunidades de desenvolvimento não me foram oferecidas } \\
\text { por minha empresa, busquei-as por mim mesmo. }\end{array}$ & $3,4 \%$ & $5,5 \%$ & $4,6 \%$ & $30,2 \%$ & $56,4 \%$ \\
\hline & Sou responsável por meu sucesso ou fracasso em minha carreira. & $1,9 \%$ & $8,9 \%$ & $1,7 \%$ & $48,2 \%$ & $39,3 \%$ \\
\hline & $\begin{array}{l}\text { De um modo geral, tenho uma carreira bastante independente e dirigida } \\
\text { por mim. }\end{array}$ & $7,9 \%$ & $12,0 \%$ & $8,9 \%$ & $50,6 \%$ & $20,6 \%$ \\
\hline & $\begin{array}{l}\text { Liberdade para escolher minha própria trajetória de carreira é um dos } \\
\text { meus valores mais importantes. }\end{array}$ & $2,9 \%$ & $5,3 \%$ & $11,0 \%$ & $40,0 \%$ & $40,8 \%$ \\
\hline & Estou no comando da minha própria carreira. & $6,5 \%$ & $12,0 \%$ & $6,0 \%$ & $48,9 \%$ & $26,6 \%$ \\
\hline & $\begin{array}{l}\text { No final das contas, dependo de mim mesmo para avançar em minha } \\
\text { carreira. }\end{array}$ & $6,2 \%$ & $13,4 \%$ & $4,1 \%$ & $49,4 \%$ & $26,9 \%$ \\
\hline & No que diz respeito à minha carreira, quem toma as decisões sou eu. & $5,3 \%$ & $14,4 \%$ & $3,4 \%$ & $47,0 \%$ & $30,0 \%$ \\
\hline & $\begin{array}{l}\text { Em minhas experiências passadas, confiei mais em mim mesmo do que } \\
\text { em outras pessoas para encontrar um novo emprego, quando necessário. }\end{array}$ & $3,4 \%$ & $6,0 \%$ & $10,6 \%$ & $30,7 \%$ & $49,4 \%$ \\
\hline \multirow{6}{*}{ 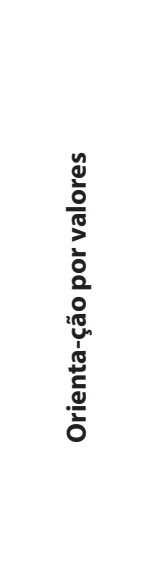 } & $\begin{array}{l}\text { Eu conduzo minha própria carreira, baseado(a) em minhas prioridades } \\
\text { pessoais e não nas prioridades do meu empregador. }\end{array}$ & $8,9 \%$ & $21,1 \%$ & $9,4 \%$ & $42,7 \%$ & $18,0 \%$ \\
\hline & $\begin{array}{l}\text { Não é muito importante para mim a forma com que as outras pessoas } \\
\text { avaliam as escolhas que eu faço em minha carreira. }\end{array}$ & $8,6 \%$ & $26,9 \%$ & $9,4 \%$ & $36,5 \%$ & $18,7 \%$ \\
\hline & $\begin{array}{l}\text { O que mais importa para mim é como eu me sinto em relação a meu } \\
\text { sucesso na carreira e não como outras pessoas se sentem a respeito disso. }\end{array}$ & $5,0 \%$ & $18,0 \%$ & $6,5 \%$ & $30,5 \%$ & $40,0 \%$ \\
\hline & $\begin{array}{l}\text { Sigo a minha própria consciência se a empresa solicitar que eu faça algo } \\
\text { que seja contra os meus valores. }\end{array}$ & $5,5 \%$ & $7,7 \%$ & $7,7 \%$ & $29,5 \%$ & $49,6 \%$ \\
\hline & $\begin{array}{l}\text { O que eu acho que está certo em minha carreira é mais importante do } \\
\text { que o que minha empresa acha. }\end{array}$ & $7,9 \%$ & $22,1 \%$ & $13,2 \%$ & $40,8 \%$ & $16,1 \%$ \\
\hline & $\begin{array}{l}\text { Em minhas experiências passadas, eu segui meus próprios valores } \\
\text { mesmo quando a empresa me pediu para fazer algo com o qual eu não } \\
\text { concordava. }\end{array}$ & $8,2 \%$ & $14,9 \%$ & $17,3 \%$ & $30,9 \%$ & $28,8 \%$ \\
\hline
\end{tabular}

Fonte: Elaborada pelos autores (2018).

Legenda: 1 =discordo totalmente; 2 = discordo parcialmente; 3 = não concordo nem discordo; 4 = concordo parcialmente; $5=$ concordo totalmente.

Tabela 04 Análise dos construtos da carreira proteana

\begin{tabular}{|c|c|c|c|c|c|c|}
\hline & \multirow{2}{*}{ Média } & \multirow{2}{*}{ Mediana } & \multirow{2}{*}{$\begin{array}{l}\text { Desvio-pa- } \\
\text { drão }\end{array}$} & \multicolumn{3}{|c|}{ Percentis } \\
\hline & & & & 25 & 50 & 75 \\
\hline Autodirecionamento de carreira & $79,3 \%$ & $82,5 \%$ & $14,3 \%$ & $70,0 \%$ & $82,5 \%$ & $90,0 \%$ \\
\hline Orientação por valores & $71,8 \%$ & $76,7 \%$ & $17,1 \%$ & $60,0 \%$ & $76,7 \%$ & $83,3 \%$ \\
\hline
\end{tabular}

Fonte: Elaborada pelos autores (2018). 


\subsection{Dimensões da satisfação no trabalho}

A análise dos resultados considera que, quanto maior o valor, maior será o grau de satisfação do empregado com a dimensão de seu trabalho. $\mathrm{Na}$ tabela 05 , observa-se, quanto à satisfação, que, de forma geral, os servidores estão mais satisfeitos com colegas e com as chefias, tendo-se como destaque a satisfação com a forma como o chefe trata o servidor, sendo observado o maior grau de respostas do tipo "muito satisfeito".

Com relação à satisfação com o salário, foram encontradas as maiores ocorrências de insatisfação, com particular ênfase à satisfação salarial em relação à capacidade profissional do servidor. Foi constatado certo equilíbrio nas respostas relativas à satisfação com as promoções, particularmente no que se refere ao número de vezes em que o servidor foi promovido sendo encontrado o maior número de respostas do tipo "indiferente", destaca-se ainda que esses valores estão muito próximos aos encontrados como "insatisfeito" e "satisfeito".

Ainda a respeito da satisfação com promoções, a maneira como a instituição promove seu pessoal foi, na pesquisa, o alvo das maiores respostas do tipo "muito insatisfeito", que, em conjunto com os insatisfeitos, no mesmo item, forma o ponto da pesquisa com maior ocorrência de descontentamento (quase $60 \%$ dos entrevistados). Deve-se frisar que esse ponto é regulado pela Lei $\mathrm{n}^{\circ} 11.091 / 2005$, com as administrações das universidades não tendo muitas oportunidades de atuar de forma flexível. Em uma lógica proteana, os servidores devem explorar seus potenciais de buscarem planos de carreiras pessoais muito além das oportunidades oferecidas pelo cargo público (SILVA; BALASSIANO; SILVA, 2014).

As dimensões que promovem maior satisfação aos servidores são colegas e chefia, confirmando a segunda hipótese desta pesquisa. Esses resultados corroboram pesquisas anteriores realizadas em outras entidades governamentais, como a realizada por Brandão et al. (2014), a qual concluiu que os servidores públicos estão mais satisfeitos com supervisão e com relacionamentos interpessoais. Quanto à satisfação com as promoções, verifica-se o menor percentual de satisfação $(56,9 \%)$.
De acordo com os achados, atesta-se que tanto as atitudes da carreira proteana quanto as dimensões de satisfação apresentaram valores percentuais acima de $50 \%$, sendo consideradas moderadas ou fortes. Pela análise dos percentis, ressalva-se que os menores níveis, abaixo de $50 \%$, estão localizados nas variáveis satisfação com o salário e com as promoções, pois $25 \%$ das respostas da amostra apontam para não satisfeitos, tendo, respectivamente, valores abaixo de $40 \%$ e $46,7 \%$. Os resultados completos podem ser observados na tabela 06 .

É apresentada, a seguir, a relação entre as atitudes da carreira proteana e as dimensões da satisfação no trabalho, a partir dos dados obtidos na pesquisa.

\subsection{Relação entre carreira proteana e satisfação no trabalho}

Pelo teste de correlação de Spearman, verificou-se que existem correlações significativas entre a maioria dos construtos. É possível observar, na tabela 07 , que a maioria das correlações está abaixo de 0,4 , ou seja, são consideradas como fracas. Observou-se correlação positiva com significância estatística de magnitude moderada entre os seguintes itens: orientação por valores e autodirecionamento $(0,427)$; satisfação com as promoções e satisfação com salário $(0,528)$; e satisfação com as promoções e satisfação com a natureza do trabalho $(0,584)$.

Constatou-se que as correlações significativas existentes entre $\mathrm{o}$ autodirecionamento $\mathrm{e}$ as dimensões da satisfação no trabalho são fracas (satisfação com a natureza do trabalho e satisfação com as promoções). Por meio dos resultados, confirma-se parcialmente a terceira hipótese, a partir da qual é possível constatar que existe relação entre o autodirecionamento e as dimensões da satisfação no trabalho.

Observou-se ainda que a orientação por valores somente tem correlação significativa com satisfação com a chefia, porém esse resultado é considerado fraco. Assim, por meio dos resultados, confirma-se parcialmente a quarta hipótese, pois é possível constatar que existe relação entre orientação por valores e as dimensões da satisfação no trabalho. 
Tabela 05 Afirmativas sobre satisfação

\begin{tabular}{|c|c|c|c|c|c|c|}
\hline Dimensões & Variáveis & 1 & 2 & 3 & 4 & 5 \\
\hline \multirow{3}{*}{$\begin{array}{l}\text { Satisfação } \\
\text { com os colegas }\end{array}$} & Com o espírito de colaboração dos meus colegas de trabalho & $3,4 \%$ & $14,4 \%$ & $7,4 \%$ & $55,2 \%$ & $19,7 \%$ \\
\hline & Com a confiança que eu posso ter em meus colegas de trabalho & $3,6 \%$ & $13,4 \%$ & $10,8 \%$ & $55,9 \%$ & $16,3 \%$ \\
\hline & Com o tipo de amizade que meus colegas demonstram por mim & $2,2 \%$ & $7,0 \%$ & $11,3 \%$ & $60,0 \%$ & $19,7 \%$ \\
\hline \multirow{3}{*}{$\begin{array}{l}\text { Satisfação } \\
\text { com o salário }\end{array}$} & Com o meu salário comparado com o quanto eu trabalho. & $7,0 \%$ & $29,3 \%$ & $7,9 \%$ & $49,9 \%$ & $6,0 \%$ \\
\hline & Com o meu salário comparado à minha capacidade profissional. & $13,9 \%$ & $39,6 \%$ & $10,3 \%$ & $32,1 \%$ & $4,1 \%$ \\
\hline & Com meu salário comparado aos meus esforços no trabalho & $9,1 \%$ & $35,3 \%$ & $7,7 \%$ & $42,9 \%$ & $5,0 \%$ \\
\hline \multirow{3}{*}{$\begin{array}{l}\text { Satisfação } \\
\text { com a chefia }\end{array}$} & Com a capacidade profissional do meu chefe & $6,2 \%$ & $11,8 \%$ & $12,2 \%$ & $48,4 \%$ & $21,3 \%$ \\
\hline & Com o entendimento entre eu e meu chefe. & $3,6 \%$ & $7,4 \%$ & $9,6 \%$ & $50,4 \%$ & $29,0 \%$ \\
\hline & Com a maneira como meu chefe me trata & $3,1 \%$ & $6,7 \%$ & $11,3 \%$ & $44,4 \%$ & $34,5 \%$ \\
\hline \multirow{3}{*}{$\begin{array}{l}\text { Satisfação com } \\
\text { a natureza do } \\
\text { trabalho }\end{array}$} & Com a variedade de tarefas que realizo & $4,1 \%$ & $17,0 \%$ & $14,1 \%$ & $56,4 \%$ & $8,4 \%$ \\
\hline & Com o grau de interesse que minhas tarefas me despertam & $4,1 \%$ & $13,9 \%$ & $14,1 \%$ & $55,9 \%$ & $12,0 \%$ \\
\hline & Com a capacidade de meu trabalho absorver-me & $5,3 \%$ & $19,7 \%$ & $19,2 \%$ & $49,4 \%$ & $6,5 \%$ \\
\hline \multirow{3}{*}{$\begin{array}{l}\text { Satisfação com } \\
\text { as promoções }\end{array}$} & Com o número de vezes que já fui promovido nesta empresa. & $14,9 \%$ & $29,0 \%$ & $27,3 \%$ & $26,6 \%$ & $2,2 \%$ \\
\hline & Com a maneira como a instituição promove seu pessoal & $20,6 \%$ & $37,2 \%$ & $20,9 \%$ & $19,7 \%$ & $1,7 \%$ \\
\hline & Com a variedade de tarefas que realizo & $5,8 \%$ & $18,2 \%$ & $14,9 \%$ & $56,4 \%$ & $4,8 \%$ \\
\hline
\end{tabular}

Fonte: Elaborada pelos autores (2018).

Legenda: 1 = muito insatisfeito; 2 = insatisfeito; 3 = indiferente; 4 = satisfeito; e 5 = muito satisfeito.

Tabela 06 Análise dos construtos de satisfação do trabalho

\begin{tabular}{l|c|c|c|c|c|c} 
& & Média & Mediana & $\begin{array}{c}\text { Desvio-pa- } \\
\text { drão }\end{array}$ & \multicolumn{3}{|c}{ Percentis } \\
\cline { 5 - 8 } & & & $\mathbf{2 5}$ & $\mathbf{5 0}$ & $\mathbf{7 5}$ \\
\hline Satisfação com os colegas & $75,3 \%$ & $80,0 \%$ & $17,6 \%$ & $66,7 \%$ & $80,0 \%$ & $86,7 \%$ \\
\hline Satisfação com o salário & $59,4 \%$ & $60,0 \%$ & $21,2 \%$ & $40,0 \%$ & $60,0 \%$ & $80,0 \%$ \\
\hline Satisfação com a chefia & $77,4 \%$ & $80,0 \%$ & $18,9 \%$ & $66,7 \%$ & $80,0 \%$ & $93,3 \%$ \\
\hline Satisfação com a natureza do trabalho & $69,2 \%$ & $80,0 \%$ & $18,1 \%$ & $60,0 \%$ & $80,0 \%$ & $80,0 \%$ \\
\hline Satisfação com as promoções & $56,9 \%$ & $60,0 \%$ & $17,0 \%$ & $46,7 \%$ & $60,0 \%$ & $66,7 \%$ \\
\hline
\end{tabular}

Fonte: Elaborada pelos autores (2018).

Tabela 07 Teste de correlação

\begin{tabular}{l|c|c|c|c|c|c|c}
\hline Autodirecionamento & 1 & & & & & & \\
\hline Orientação por valores & $0,427^{* *}$ & 1 & & & & & \\
\hline Satisfação com os colegas & 0,064 & 0,072 & 1 & & & & \\
\hline Satisfação com o salário & 0,096 & 0,007 & $0,200^{* *}$ & 1 & & & \\
\hline Satisfação com a chefia & 0,085 & $0,104^{*}$ & $0,379^{* *}$ & 0,071 & 1 & & \\
\hline Satisfação com a natureza do trabalho & $0,217^{* *}$ & 0,094 & $0,352^{* *}$ & $0,368^{* *}$ & $0,334^{* *}$ & 1 & \\
\hline Satisfação com as promoçães & $0,147^{* *}$ & 0,022 & $0,286^{* *}$ & $0,528^{* *}$ & $0,312^{* *}$ & $0,584^{* *}$ & 1 \\
\hline
\end{tabular}

Fonte: Elaborada pelos autores (2018). 


\subsection{Análise de árvore de decisão}

Conforme Hair Jr. et al. (2006), a árvore de decisão é uma partição sequencial de um conjunto de dados, com intuito de maximizar as diferenças apresentadas da variável dependente. Esse método foi utilizado para os construtos estimados da carreira proteana (autodirecionamento e orientação por valores), a fim de segmentar esses construtos, tendo como critérios as informações básicas dos respondentes: idade, escolaridade, tempo de trabalho e níveis de satisfação. As árvores de decisão, neste estudo, servem para identificar qual ou quais os perfis de respondentes mostraram maior nível de autodirecionamento e orientação por valores.

\subsubsection{Autodirecionamento de carreira}

Pelos dados, observou-se aprimoramento da classificação de autodirecionamento ao segmentar as observações na sequência: orientação por valores, satisfação com as promoções e o tempo de trabalho no órgão. Ao contrapor os resultados gerais da percentagem de respondentes com forte autodirecionamento de carreira e dos gerados pela árvore de decisão, observa-se a identificação de perfis que apresentam maior autodirecionamento, de acordo com a tabela 08 .

Pela figura 1, identifica-se que o perfil com maior percentagem de respondentes com forte autodire- cionamento de carreira é observado no nó terminal $6(93,3 \%)$, o qual inclui os respondentes com tempo de trabalho ao longo da carreira entre 3 e 10 anos; de nível de satisfação com promoções moderada ou forte; e com forte orientação por valores. Por outro lado, o perfil de respondentes com menor percentagem é apresentado pelo nó terminal 2 (58,5\%), sendo formado por respondentes com moderada, regular ou fraca orientação por valores. Assim, por meio dos resultados, confirma-se a quinta hipótese, ou seja, os respondentes com maior nível de autodirecionamento são aqueles com menor tempo de trabalho ao longo da carreira.

\subsubsection{Orientação por valores}

Pelos dados dos respondentes, observou-se aprimoramento da classificação de orientação ao segmentar as observações na sequência: autodirecionamento de carreira, estado civil e faixa etária. Ao contrapor os resultados gerais da percentagem de respondentes com forte orientação por valores e dos gerados pela árvore de regressão, observa-se a identificação de perfis que apresentam maior orientação, conforme a tabela 09 .

Na figura 02 , identifica-se que o perfil com maior percentagem de respondentes com forte orientação por valores é observado no nó terminal 8 (82\%), o qual inclui os respondentes de 35 a 44 anos ou acima de 55 anos, solteiros ou divorciados/separados e com

Tabela 08 Análise da árvore de decisão sobre autodirecionamento da carreira

\begin{tabular}{|c|c|c|c|c|c|}
\hline \multirow{2}{*}{ Nó } & \multirow{2}{*}{ Forte } & \multirow{2}{*}{ Nó pai } & \multicolumn{3}{|c|}{ Variável independente principal } \\
\hline & & & Variável & Melhoria & Valores divididos \\
\hline 0 & $71,2 \%$ & & & & \\
\hline 1 & $83,8 \%$ & 0 & Orientação por valores & 0,0267 & Forte \\
\hline 2 & $58,5 \%$ & 0 & Orientação por valores & 0,0267 & Moderada; Regular; Fraca \\
\hline 3 & $89,1 \%$ & 1 & Satisfação com as promoções & 0,0050 & Moderada; Forte \\
\hline 4 & $73,6 \%$ & 1 & Satisfação com as promoções & 0,0050 & Regular; Fraca \\
\hline 5 & $87,1 \%$ & 3 & Tempo de trabalho & 0,0012 & mais de 20 anos; de 10 a 20 anos; de 2 a 3 anos \\
\hline 6 & $93,3 \%$ & 3 & Tempo de trabalho & 0,0012 & de 3 a 5 anos; de 5 a 10 anos \\
\hline 7 & $88,9 \%$ & 6 & Estado Civil & 0,0005 & Casado/União Estável \\
\hline 8 & $96,3 \%$ & 6 & Estado Civil & 0,0005 & Solteiro; Divorciado/Separado \\
\hline
\end{tabular}

Fonte: Elaborada pelos autores (2018). 
Figura 1 Árvore de decisão de auto direcionamento de carreira

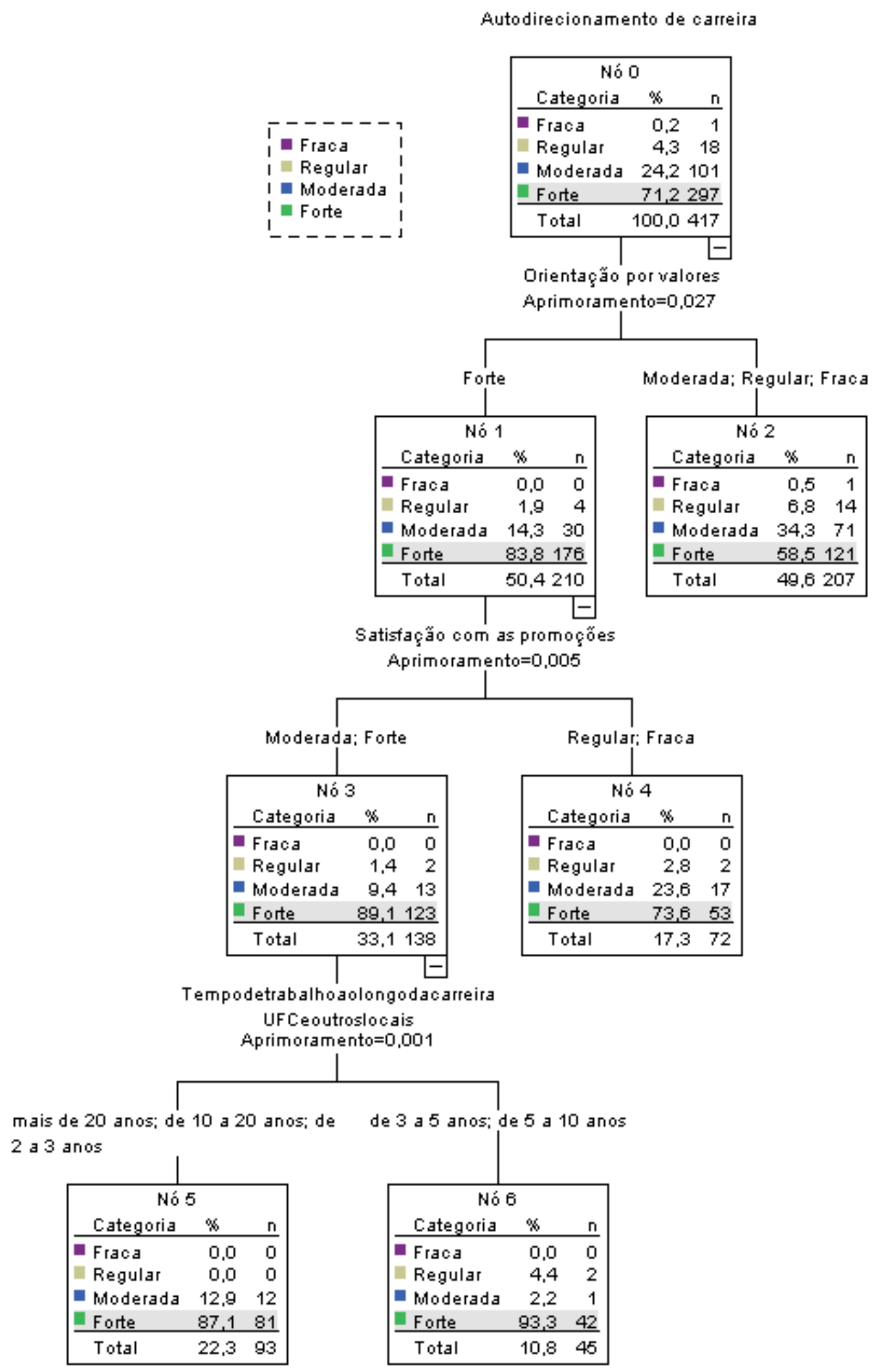

Fonte: Dados da pesquisa (2018). 
Tabela 09 Análise da árvore de decisão sobre valores da carreira

\begin{tabular}{|c|c|c|c|c|c|}
\hline \multirow{2}{*}{ Nó } & \multirow{2}{*}{ Forte } & \multirow{2}{*}{ Nó pai } & \multicolumn{3}{|c|}{ Variável independente principal } \\
\hline & & & Variável & Melhoria & Valores divididos \\
\hline 0 & $50,4 \%$ & & & & \\
\hline 1 & $59,3 \%$ & 0 & Autodirecionamento & 0,029 & Forte \\
\hline 2 & $28,3 \%$ & 0 & Autodirecionamento & 0,029 & Moderada; Regular; Fraca \\
\hline 3 & $48,6 \%$ & 1 & Estado Civil & 0,015 & Casado/União Estável \\
\hline 4 & $69,5 \%$ & 1 & Estado Civil & 0,015 & Solteiro; Divorciado/Separado \\
\hline 5 & $59,3 \%$ & 3 & Tempo de trabalho & 0,013 & mais de 20 anos; de 10 a 20 anos \\
\hline 6 & $35,4 \%$ & 3 & Tempo de trabalho & 0,013 & de 2 a 3 anos; de 3 a 5 anos; de 5 a 10 anos \\
\hline 7 & $61,1 \%$ & 4 & Faixa etária & 0,008 & de 45 a 54 anos; de 25 a 34 anos; até 24 anos \\
\hline 8 & $82,0 \%$ & 4 & Faixa etária & 0,008 & de 35 a 44 anos; acima de 55 anos \\
\hline 9 & $40,7 \%$ & 5 & Satisf. com a natureza do trabalho & 0,009 & Moderada \\
\hline 10 & $68,5 \%$ & 5 & Satisf. com a natureza do trabalho & 0,009 & Forte; Regular \\
\hline
\end{tabular}

Fonte: Elaborada pelos autores (2018).

forte autodirecionamento de carreira; enquanto o perfil de respondentes com menor percentagem é apresentado pelo nó terminal 2 (28,3\%), sendo formado por respondentes com moderado, regular ou fraco autodirecionamento de carreira. Dessa forma, a sexta hipótese é confirmada, pois os respondentes com maior nível de orientação por valores possuem também forte autodirecionamento.

A seguir, será discutida a confiabilidade da escala na formação dos escores totais obtidos pela pesquisa.

\subsection{Teste de confiabilidade}

A confiabilidade de consistência interna, segundo Hair Jr et al. (2006), é também chamada de coeficiente alfa, e, para obtê-lo, calcula-se a média dos coeficientes de todas as correlações possíveis entre duas metades divididas. Esse valor pode variar de 0 até 1 , sendo que é normalmente considerado um alfa de 0,7 como mínimo aceitável, embora coeficientes mais baixos possam ser aceitáveis, dependendo dos objetivos da pesquisa.

Conforme a tabela 10 , pode-se constatar que todos os construtos apresentam valores acima de 0,70. Nota-se, então, que os itens do questionário estão correlacionados entre si e com o resultado geral da pesquisa. No próximo tópico, serão expostos, de maneira mais direta, os resultados obtidos.

\section{CONCLUSÃO}

Os servidores técnico-administrativos da UFC apresentaram um forte autodirecionamento de carreira $(79,3 \%)$ e moderada orientação por valores $(71,8 \%)$. Quanto às dimensões da satisfação no trabalho, os servidores mostraram-se predominantemente mais satisfeitos com o relacionamento entre os colegas e com a chefia, corroborando estudos anteriores realizados com servidores públicos de outras instituições.

Posteriormente, foi verificado, no teste de correlação, que as relações existentes entre o autodirecionamento e as dimensões da satisfação no trabalho são fracas (satisfação com a natureza do trabalho e satisfação com as promoções). Observou-se ainda que a orientação por valores somente tem correlação significativa com satisfação com a chefia, porém esse resultado é considerado fraco.

Por fim, foram identificados os perfis de respondentes com maior nível de autodirecionamento, utilizando-se do método da árvore de decisão. Assim, o perfil com maior percentagem de respondentes com forte autodirecionamento de carreira é observado com os respondentes com tempo de trabalho ao longo da carreira entre 3 e 10 anos; de nível de satisfação com promoções moderada ou forte; e com forte orientação por valores. Em relação ao sexto objetivo específico - identificar os perfis de respon- 
Figura 02 Árvore de decisão de orientação por valores.

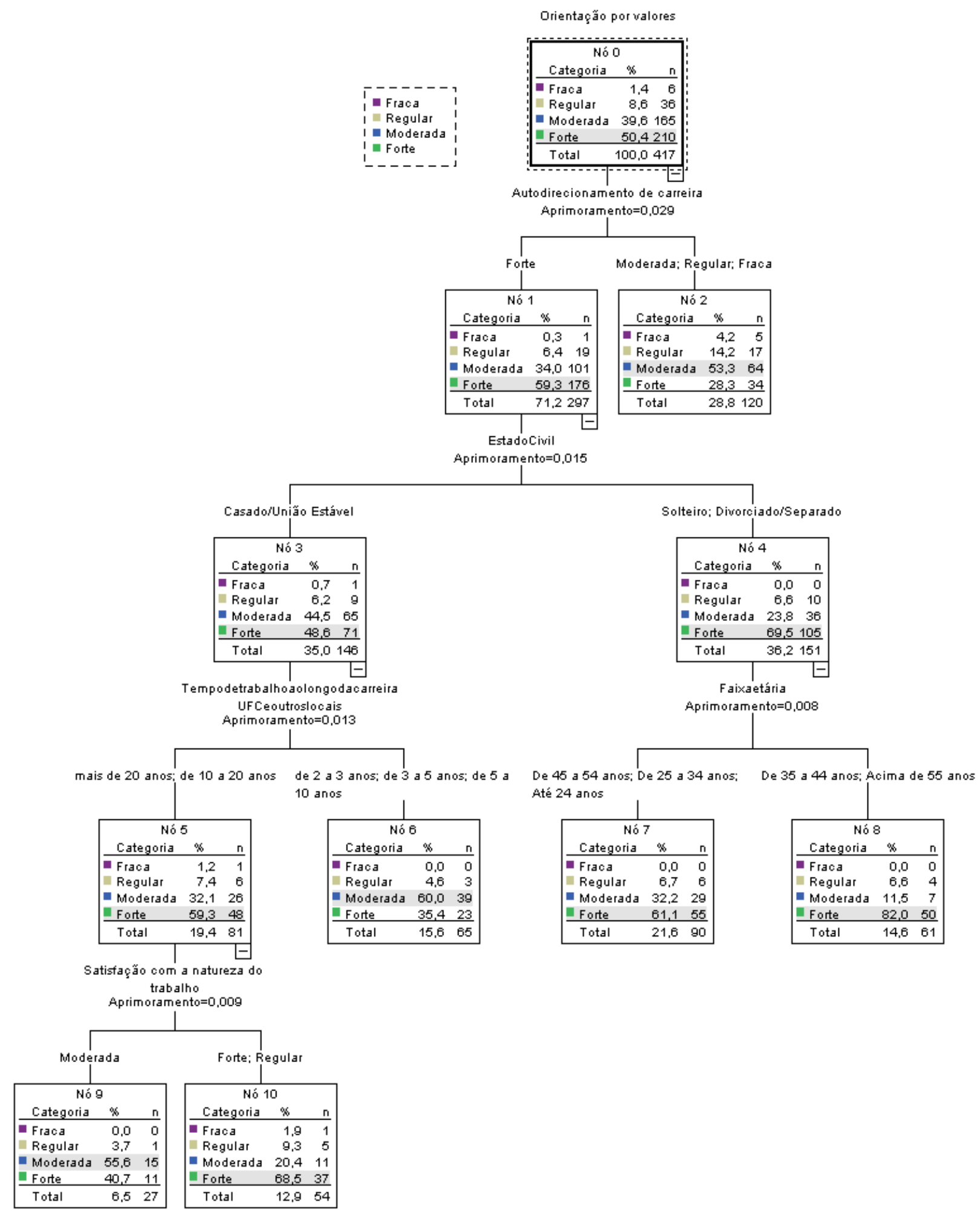

Fonte: Dados da pesquisa (2018). 
Tabela 10 Teste de confiabilidade

\begin{tabular}{l|c|c}
\hline & Alfa de Cronbach & № de itens \\
\hline Autodirecionamento & 0,810 & 8 \\
\hline Orientação por valores & 0,776 & 6 \\
\hline Satisfação com os colegas & 0,883 & 3 \\
\hline Satisfação com o salário & 0,905 & 3 \\
\hline Satisfação com a chefia & 0,887 & 3 \\
\hline Satisfação com a natureza do trabalho & 0,872 & 3 \\
\hline Satisfação com as promoções & 0,723 & 3 \\
\hline
\end{tabular}

Fonte: Elaborada pelos autores (2018).

dentes com maior nível de orientação por valores - verificou-se que o perfil com maior percentagem de respondentes com forte orientação por valores é observado nos respondentes de 35 a 44 anos ou acima de 55 anos, solteiros ou divorciados/separados e com forte autodirecionamento de carreira. Diante disso, por meio dos resultados, confirma-se a H5, ou seja, os respondentes com maior nível de autodirecionamento são aqueles com menor tempo de trabalho ao longo da carreira. A H6 também é confirmada, pois os respondentes com maior nível de orientação por valores possuem também forte autodirecionamento.

Diante do exposto, este trabalho veio somar-se a outros estudos empíricos realizados em âmbito governamental. Ressalta-se que não foram encontradas outras pesquisas que estudassem a relação entre as atitudes da carreira proteana e as dimensões da satisfação no trabalho. A mais, destaca-se que as evidências encontradas contribuem também para a gestão de pessoas da própria UFC.

Os resultados deste estudo, entretanto, não podem ser generalizados para toda a administração pública brasileira, tendo em vista a pesquisa ter abarcado apenas um grupo de servidores da UFC, servindo para a própria administração da unidade pesquisada e para comparação com outros estudos. Outra limitação, encontrada em surveys sociais, é que nem todos os questionários enviados foram respondidos. Assim, o tamanho da amostra é um aspecto que limita os resultados do trabalho.

Sugere-se que sejam feitos outros estudos sobre o tema de atitudes de carreira e satisfação no serviço público, em entidades distintas e, até mesmo, nas diversas universidades de diferentes unidades terri- toriais, a fim de compreender melhor os fatores que geram satisfação nos agentes públicos e aqueles que produzem insatisfação, bem como a relação entre o nível de satisfação desse grupo peculiar e suas atitudes de carreira. Sugere-se ainda a ampliação com a utilização de comparações com a carreira de servidores docentes.

\section{REFERÊNCIAS}

ANDRADE, G. A.; KILIMNIK, Z. M.; PARDINI, D. J. Carreira tradicional versus carreira autodirigida ou proteana: um estudo comparativo sobre a satisfação com a carreira, a profissão e o trabalho. Revista de Ciências da Administração, Florianópolis, v. 13, n. 31, p. 58-80, 2011.

ANDRADE, G. A. Articulações na carreira pública: uma análise do comprometimento com a carreira dos servidores técnico-administrativos de uma universidade federal. Revista de Carreiras e Pessoas, São Paulo, v. 8, n. 3, p. 331-342, 2018.

BARBOSA, Flavia L. S. et al. Visão multidimensional da satisfação do trabalho: um estudo em um hospital público piauiense. Revista de Gestão - Rege, São Paulo, v. 23, p. 99-110, 2016.

BENDASSOLLI, Pedro F. Recomposição da relação sujeito-trabalho nos modelos emergentes de carreira. Revista de Administração de Empresas, São Paulo, v. 49, n. 4 , p. $387-400,2009$. 
BIZARRIA, F. P. A.; BARBOSA, F. L. S.; MOREIRA, M. Z.; RABÊLO NETO, A. Análise estrutural de relações entre motivação, satisfação e sugestões criativas. BASE - Revista de Administração e Contabilidade da UNISINOS, São Leopoldo, v. 15, n. 2, p. 82-94, 2018.

BRANDÃO, I. F.; LIMA, L. C.; CABRAL, A. C. A.; SANTOS, S. M. D.; PESSOA, M. N. M. Satisfação no serviço público: um estudo na Superintendência Regional do Trabalho e Emprego no Ceará. REAd. Revista Eletrônica de Administração, Porto Alegre, v. 20, n. 1, p. 90-113, 2014.

BRASIL. Plano de Carreira dos Cargos TécnicoAdministrativos em Educação (PCCTAE): Lei no 11.091, de 12 de janeiro de 2005. Brasília, 2005. Disponível em: http://www.planalto.gov. br/ccivil_03/_ato2004-2006/2005/lei/l11091.htm. Acesso em: 25 fev. 2019.

BRISCOE, J. P.; HALL, D. T.; DEMUTH, R. L. F. Protean and boundaryless careers: An empirical exploration. Journal of Vocational Behaviour, [S. 1.], v. 69 , n. 1, p. 30-47, 2006.

CÁLCENA, Esteban J. F.; CASADO, Tania. Desafios e riscos na gestão da própria carreira. In: DUTRA, Joel S.; VELOSO, Elza F. R. (Org.). Desafios da gestão de carreira. São Paulo: Atlas, 2013. p. 39-52.

CHANLAT, Jean-François. Quais carreiras para qual sociedade? Revista de Administração de Empresas, São Paulo, v. 35, n. 6, p. 67-75, 1995.

CORdeiro, H. T. D.; AlbuQUerque, L. G. Validação da escala de atitudes de carreira sem fronteiras e carreira proteana no Brasil. Revista de Carreiras e Pessoas, São Paulo, v. 6, n. 2, p. 118-137, 2016.

CRESWELL, John W. Projeto de pesquisa: métodos qualitativo e quantitativo. 3. ed., Porto Alegre: Atmed, 2010.

GIL, A. C. Como elaborar projetos de pesquisa. 4. ed. São Paulo: Atlas, 2009.
GREENHAUS, Jeffrey H.; Callanan, Gerald A. C. Career Management. 2. ed. Pensilvânia: Dryden Press, 1994.

HAIRJr, J.F.; BLACK, W.C.; BABIN, B. J.; ANDERSON, R. E.; TATHAM, R. L. Multivariate Data Analysis. 6. ed. Upper Saddle River, NJ: Pearson Prentice Hall, 2006.

HALL, D. T. Protean careers of the 21st Century. The Academy of Management Executive, [S. 1.], v. 10, n. 4, p. 8-16, 1996.

. Careers in and out of organizations.

Londres: Sage, 2002.

The protean career: A quarter-century journey. Journal of Vocational Behaviour. [S. 1.], n.1, v.65, p. 1-13, maio, 2004.

HERZBERG, F. Mais uma vez: como motivar seus funcionários. In: VROOM, V. Gestão de pessoas, não de pessoal: os melhores métodos de motivação e avaliação de desempenho. Trad. de Ana Beatriz Rodrigues e Priscilla Martins Celeste. Rio de Janeiro: Campus, 1997. p. 55-81.

KILIMNIK, Z. M.; VISENTIN, I. C. Evolução dos estudos internacionais sobre o tema carreira. Revista de Carreiras e Pessoas, São Paulo, v. 4, n. 2, p. 204211, 2014.

LOCKE, E. A. The nature and causes of job satisfaction. In: Dunnette, M. P. (Org.). Handbook of industrial and organizational psychology. Chicago: Rand-McNally, 1976. p. 1294-1349.

LOUREIRO, C. M. P.; DA COSTA, I. S. A.; FREITAS, J. A. S. B. Trajetórias profissionais de mulheres executivas: qual o preço do sucesso? Revista de Ciências da Administração, Florianópolis, v. 14, n. 33, p. 130-144, 2012.

MARTINS, Gilberto de Andrade. Manual para elaboração de monografias e dissertações. 3. ed. São Paulo: Atlas, 2007. 
MARTINS, Hélio Tadeu. Gestão de carreiras na era do conhecimento: abordagem conceitual e resultados de pesquisa. 2. ed. Rio de Janeiro: Qualitymark, 2011.

MOTTA, F. C. P. Teoria geral da administração. 7. ed. São Paulo: Pioneira, 1979.

NEVES, Mônica Maria; TREVISAN, Leonardo Nelmi; JOÃO, Belmiro do Nascimento. Carreira proteana: revisão teórica e análise bibliométrica. Revista Psicologia: Organizações e Trabalho, Florianópolis, v. 13, n. 2, p. 217-232, 2013.

PINHO, E. C. S. N.; KILIMNIK, Z. M.; ANDRADE, D. F. A influência da estrutura matricial no comprometimento com a carreira em comparação com a estrutura tradicional: um estudo de caso na Emater-MG. Revista de Gestão, São Paulo, v. 22, n. 2, p. 1-17, 2015.

PRÓ-REITORIA DE GESTÃO DE PESSOAS DA UFC. Quadro de referência de servidores técnico-administrativos. Fortaleza: UFC. Disponível em: https://progep.ufc.br/wp-content/uploads/2015/02/ quant-serv-dez-2017.pdf. Acesso em: 1 jul. 2018.

SILVA, Jefferson de Alcantara. Estudo comparativo dos modelos de carreira proteana e carreira sem fronteiras por meio de escalas de atitudes. 2009. 101 f. Dissertação (Mestrado em Administração) - Faculdade de Gestão e Negócios, Universidade Federal de Uberlândia, Uberlândia, 2009.

SILVA, J. R.; BALASSIANO, M.; SILVA, A. R. L. Burocrata proteano: articulações de carreira em torno e além do setor público. Revista de Administração Contemporânea, Maringá, v. 18, n. 1, p. 1-19, 2014.

SILVA, Lindomar Pinto da; CASTRO, Miguel Angel Rivera; DOS-SANTOS, Marcos Gilberto. Influência da Cultura Organizacional Mediada pelo Assédio Moral na Satisfação no Trabalho. Rev. adm. contemp., Curitiba, v. 22, n. 2, p. 249-270, 2018.
SIQUEIRA, M. M. M. Satisfação no trabalho. In: SIQUEIRA, M. M. M. et al. Medidas do Comportamento Organizacional: ferramentas de diagnóstico e de gestão. São Paulo: Artmed Editora S.A., 2008. p. 265-274. 